Images

\title{
Why is my arm swollen?
}

\author{
Warren J. Cheung, MD*; Bruce W.A. Cload, PhD, $\mathrm{MD}^{\dagger}$; Dalibor Kubelik, MDCM ${ }^{\ddagger}$
}

\section{CASE HISTORY}

A 49-year-old female presented to the emergency department with a 3-day history of a painful swollen right arm. Tooth brushing and hair washing exacerbated her symptoms. Her medical history included a right clavicle fracture from more than 20 years ago, chronic glomerulonephritis, and, within the previous 2 years, occipital ischemic stroke with persistent visual field deficits, right brachial artery thrombus, and right arm deep vein thrombosis (DVT). Her thrombi had been attributed to previous lower arm trauma with negative investigations for hypercoagulable state and malignancy. Her only medication was $81 \mathrm{mg}$ aspirin daily, and she did not report food or drug allergies. The patient's main concern was recurrence of her DVT as her warfarin had been recently discontinued in agreement with her physician.

On examination, the patient was not distressed, with blood pressure of 168/100 $\mathrm{mm} \mathrm{Hg}$, pulse of 69 beats/min, room air oxygen saturation of $99 \%$, and temperature of $36.7^{\circ} \mathrm{C}$. In comparison with the left forearm, the right forearm was pale and mildly swollen without prominent veins. There was also equal warmth, light touch sensation, and normal strength. Right brachial and ulnar pulses were palpable. The right radial pulse was attainable only by Doppler ultrasonography while in the anatomic position; however, an Allen test demonstrated good collateral flow. Abduction of the right arm beyond $180^{\circ}$ produced worsening pallor, paresthesiae, and pain (Figure 1). Further physical examination was unremarkable except for a step deformity at the distal third of the right clavicle corresponding to her remote clavicle fracture.

Bloodwork drawn at triage revealed a normal complete blood count, electrolytes, and renal function; an international normalized ratio of 1.0; and a positive D-dimer of $526 \mu \mathrm{g} / \mathrm{L}$ (negative cutoff $<300 \mu \mathrm{g} / \mathrm{L}$ ).

\section{QUESTION}

Which is the most likely diagnosis?
a) Deep vein thrombosis
b) Subclavian steal syndrome
c) Arterial thoracic outlet syndrome
d) Raynaud phenomenon

For the answer to this challenge, see page 117.

From the *Department of Emergency Medicine, The Ottawa Hospital/University of Ottawa, Ottawa, ON; tDepartment of Emergency Medicine, Saskatoon Regional Health Authority, Saskatoon, SK; ‡Division of Vascular and Endovascular Surgery, The Ottawa Hospital, Ottawa, ON.

Correspondence to: Dr. Warren J. Cheung, Department of Emergency Medicine, The Ottawa Hospital - Civic Campus, F Main, Room EM 206, 1053 Carling Avenue, Ottawa, ON K1Y 4E9; wjcheung@gmail.com.

This article has not been peer reviewed. 